\title{
Electron microscopy of high pressure frozen samples: bridging the gap between cellular ultrastructure and atomic resolution
}

\author{
Daniel Studer · Bruno M. Humbel · Matthias Chiquet
}

Accepted: 22 August 2008 / Published online: 16 September 2008

(C) Springer-Verlag 2008

\begin{abstract}
Transmission electron microscopy has provided most of what is known about the ultrastructural organization of tissues, cells, and organelles. Due to tremendous advances in crystallography and magnetic resonance imaging, almost any protein can now be modeled at atomic resolution. To fully understand the workings of biological "nanomachines" it is necessary to obtain images of intact macromolecular assemblies in situ. Although the resolution power of electron microscopes is on the atomic scale, in biological samples artifacts introduced by aldehyde fixation, dehydration and staining, but also section thickness reduces it to some nanometers. Cryofixation by high pressure freezing circumvents many of the artifacts since it allows vitrifying biological samples of about $200 \mu \mathrm{m}$ in thickness and immobilizes complex macromolecular assemblies in their native state in situ. To exploit the perfect structural preservation of frozen hydrated sections, sophisticated instruments are needed, e.g., high voltage electron microscopes equipped with precise goniometers that work at low temperature and digital cameras of high sensitivity and pixel number. With them, it is possible to generate high resolution tomograms, i.e., 3D views of subcellular structures. This review describes theory and applications of the high pressure cryofixation methodology and compares its results with those of conventional procedures.
\end{abstract}

D. Studer $(\bowtie) \cdot$ M. Chiquet

Institute for Anatomy, University of Bern,

Baltzerstr. 2, 3000 Bern 9, Switzerland

e-mail: studer@ana.unibe.ch

B. M. Humbel

Electron Microscopy and Structure Analysis,

Cellular Architecture and Dynamics, Faculty of Sciences,

Utrecht University, Padualaan 8,

3584 CH Utrecht, The Netherlands
Moreover, recent findings will be discussed showing that molecular models of proteins can be fitted into depicted organellar ultrastructure of images of frozen hydrated sections. High pressure freezing of tissue is the base which may lead to precise models of macromolecular assemblies in situ, and thus to a better understanding of the function of complex cellular structures.

Keywords High pressure freezing - Cryofixation . Electron microscopy $\cdot$ Electron tomography · Freeze substitution · Frozen hydrated sections . Immunolabeling

\section{Introduction}

Transmission electron microscopy (TEM) has proven crucial to the advancement of modern cell biology. Thanks to the much higher resolution than that achieved with a light microscope, many cellular organelles and substructures were first discovered by TEM (Palade and Porter 1954); however, it is a drawback of electron microscopy that samples containing liquid water cannot be imaged directly at room temperature. Accelerated electrons propagate only under high vacuum conditions where water is evaporating. Further, only thin layers or sections of solid matter can be viewed (Hayat 2000). In the standard procedure, biological samples are aldehyde and osmium tetroxide fixed, dehydrated, embedded into a resin, and ultra-thin sections are prepared that are stained with heavy metal ions (Luft 1961; Pease and Porter 1981). All preparation steps can introduce artifacts; fixation with glutaraldehyde and dehydration with organic solvents lead, e.g., to aggregation of proteins, collapse of highly hydrated glycans, and loss of lipids (Cope and Williams 1968, 1969a, b; Kellenberger et al. 1992). 
Moreover, the contrast seen in classical EM micrographs is based on differential adsorption of heavy metal cations to various sample components (anion formation depends on sample fixation and embedding conditions), rather than to the biological structures themselves (Hayat 2000; North et al. 1999). Thus, although atomic resolution is possible with the electron microscope in theory (and in practice with inorganic samples; Batson et al. 2002), preparation artifacts limit the effective resolution for biological specimens in practice to about $2 \mathrm{~nm}$ (Hayat 2000). As outlined in the next paragraph, cryofixation (Dubochet et al. 1988; Moor et al. 1980; Studer et al. 1989) is the basis for pushing the electron microscopic resolution toward the imaging of macromolecular assemblies in intact cells and tissues.

\section{Physical principles of cryofixation}

Ideally, one would like to image a biological specimen under conditions resembling the living state as closely as possible, i.e., when it is fully hydrated. In the vacuum of the electron microscope, this can only be achieved if all sample water is frozen (Dubochet et al. 1988); however, simple freezing of living tissue at low cooling rates (e.g., in a freezer) has disastrous effects on cellular structure and integrity. Ice forming in the cytoplasm induces phase segregation between water and solutes (organic matter and salts), with the effect that cellular components are concentrated and precipitate between ice crystal ramifications. In electron micrographs, so-called segregation patterns become visible (Allison et al. 1987; Dubochet 2007; Escaig 1982). In the worst case, growing ice crystals poke holes into cellular membranes and destroy organelles (Meryman 2007). When thawed again, such badly frozen tissues or cells are nothing but dead mush. Deleterious ice crystal formation can be avoided by pre-incubating a biological sample in anti-freeze agents that reduce the concentration of free water, such as sucrose, glycerol, DMSO, or various polymers. Since most cells survive freezing and thawing after proper anti-freeze treatment, this widely used method allows keeping single cell suspensions, small organisms, tissue pieces, even embryos viable for storage. Due to their dehydrating activity, however, anti-freeze agents introduce various alterations in cellular structure, such as severe shrinking and specific responses to osmotic stress (Meryman 2007). Although these types of changes are not lethal and reversible, the ultrastructure of such cryoprotected samples is changed. Thus, the only means to preserve ultrastructure close to the normal living state is to freeze cells or tissues in such a way that their intrinsic water turns into vitreous ("glassy") ice even in the absence of cryoprotectants (Dubochet 2007). This is achieved by very high cooling rates that do not allow water to crystallize. In consequence, water becomes a very viscous fluid, so-called amorphous (vitreous) ice.

The simplest way to obtain the cooling rates required for water vitrification is implemented in the so-called "baregrid" method (Adrian et al. 1984). In this approach a very thin sample $(<100 \mathrm{~nm})$ is plunge-frozen in, e.g., liquid ethane. In theory cooling rates as high as $10^{8} \mathrm{~K} / \mathrm{s}$ are possible. It is an inherent limitation of plunge freezing, however, that biological samples can be vitrified in the best case only to a depth of a few micrometers from their surface (Galway et al. 1995; Nitta and Kaneko 2004; Richter et al. 2007). The physical reason lies in the poor heat conduction properties of water, which causes even infinitely high superficial cooling rates to decay rapidly within the sample, until they reach a much smaller value that again allows water crystallization (Dubochet 2007; Shimoni and Muller 1998; Studer et al. 1995). The only practicable approach to vitrify thicker samples is to reduce the necessary cooling rate for vitrification. The first possibility is to add cryoprotectants; as mentioned above this is only possible with deleterious effects on ultrastructure. The alternative exploited first by Moor and his student Riehle (Moor et al. 1980; Riehle and Hoechli 1973) is to increase pressure to $210 \mathrm{MPa}$ (2,048 bar) during cooling. Water has some very remarkable properties (see Chaplin: http://www.lsbu.ac.uk/water/). Some of them may explain the pressure effect on water vitrification. Water expands during crystallization and pressure works against expansion, with the effect that at $210 \mathrm{MPa}$ the melting point of water reaches its minimum of $-22^{\circ} \mathrm{C}$. Crystalline ice has a larger specific volume (i.e., a lower density) than liquid water until the pressure of $210 \mathrm{MPa}$, in contrast to amorphous ice that is about as dense as water (Kanno et al. 1975). At higher pressures this does not hold; ice becomes denser than water and hence the melting point increases in temperature. A second reason may be the supercooling to $-92^{\circ} \mathrm{C}$ at $210 \mathrm{MPa}$, compared to $-42^{\circ} \mathrm{C}$ at ambient pressure. In cryotechnical terms, the most important effect of high pressure is a reduction in the cooling rate required to vitrify water. Whereas about several $100,000 \mathrm{~K} / \mathrm{s}$ are required to vitrify a cell at ambient pressure, a few 1,000 K/s are sufficient at $210 \mathrm{MPa}$ (Studer et al. 2001; Vanhecke et al. 2008). Because water does not conduct heat well, cooling rates of a few $1,000 \mathrm{~K} / \mathrm{s}$ are also the maximal cooling rates theoretically possible in the center of a $200 \mu \mathrm{m}$ thick aqueous sample (as depicted in Fig. 1). With very fine thermocouples, cooling rates of about $4,000 \mathrm{~K} / \mathrm{s}$ could be measured in aqueous samples of $200 \mu \mathrm{m}$ in thickness (Studer, unpublished results). These measurements confirm that theory and practice are consistent. In general, biological samples thicker than $200 \mu \mathrm{m}$ cannot be vitrified. However, in very special cases, where for any reason enormous amounts of intrinsic cryoprotectants are present (as for example the huge concentration of the protein crystallin in eye lens epithelial cells), thicker tissue pieces 


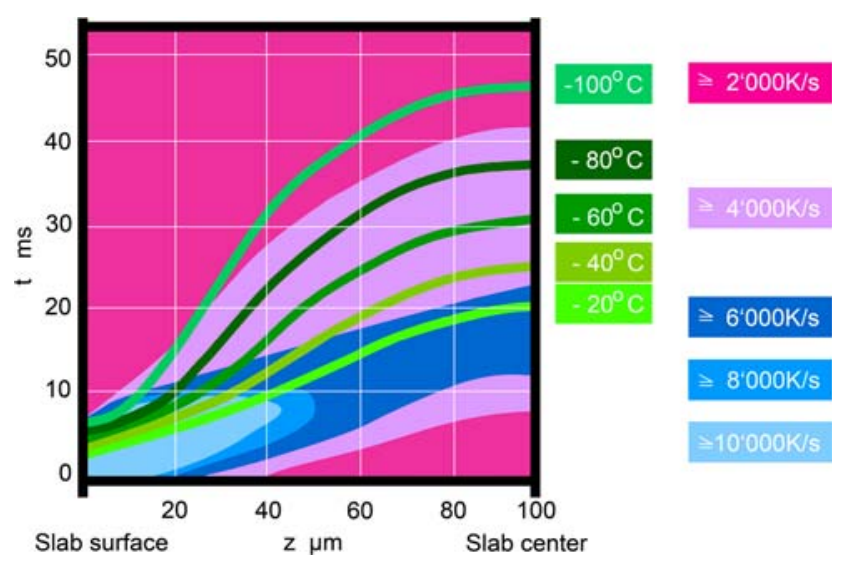

Fig. 1 This scheme shows how calculated cooling rates (shaded areas) and temperatures (curves) depend on the distance from surface $(z)$ and on time $(t)$ during freezing of an aqueous sample in an HPF device. The basics of the calculations resulting in the data presented are described in the appendix of Studer et al. (1995). The assumptions are: A slab with infinite $x, y$ dimensions and a thickness $z$ of $200 \mu \mathrm{m}$ is uniformly cooled from both surfaces with a jet of an efficient cryogen starting at time 0 , generating a superficial cooling rate of at least $10,000 \mathrm{~K} / \mathrm{s}$. In the graph, the sample surface is at left, and its center at right. On the sample surface $(z=0)$, the cooling rate is high $(>10,000 \mathrm{~K} / \mathrm{s})$ at the very beginning of cooling, and it decreases when the surface temperature approaches that of the coolant. In the center of the sample $(z=100 \mu \mathrm{m})$, the calculations show that at the start the cooling rates are quite small; a maximal cooling rate of $6,000-8,000 \mathrm{~K} / \mathrm{s}$ is achieved after $10-20 \mathrm{~ms}$ that decreases again later. When following the light green $-20^{\circ} \mathrm{C}$ isotherm (corresponding to the melting point of water at $210 \mathrm{MPa}$ ), one observes that, at any location having this temperature, the slab is cooled as rapidly as theoretically possible (cooling rates $>6,000 \mathrm{~K} / \mathrm{s}$ ). Further, one can see that $20 \mathrm{~ms}$ after the start of cooling, the slab has reached a temperature of $<-100^{\circ} \mathrm{C}$ at $25 \mu \mathrm{m}$ under the surface, whereas in the sample center at the same moment the temperature is at $-20^{\circ} \mathrm{C}$. At $210 \mathrm{MPa}$ and $-20^{\circ} \mathrm{C}$ water is still liquid and ice crystals cannot form. This "supercooling" of water is likely to be a major reason for the efficiency of high pressure freezing. After $50 \mathrm{~ms}$ the whole water slab has reached a temperature of less than $-100^{\circ} \mathrm{C}$ and water has become vitreous. It is important to realize that due to the poor heat conduction properties of water, a higher superficial cooling rate does not result in increased cooling rates within the sample; thus as experienced by many users samples thicker than $200 \mu \mathrm{m}$ cannot be vitrified

can be vitrified. Reversely, if the concentration of intrinsic cryoprotectant is very low in a specific sample, a thickness of $200 \mu \mathrm{m}$ may be too much for complete vitrification because the achievable cooling rates are too low. Nevertheless, it is correct to say that for freezing of any given sample, applying a pressure of $210 \mathrm{MPa}$ increases the thickness of the vitrified layer by a factor of ten compared to freezing at ambient pressure (as, e.g., in plunge freezing; (Sartori et al. 1993). An evident limitation of high pressure freezing is the fact that gaseous compartments collapse completely at a pressure of $210 \mathrm{MPa}$. For this reason, intercellular air-filled spaces (e.g., in plant leaves) need to be filled with a chemically inert solvent not mixable with water, as, e.g., 1-hexadecene (Studer et al. 1989).

\section{Technology of high pressure freezing and follow up procedures}

High pressure freezing (HPF) devices are currently available from three different manufacturers (Leica EMPACT and Bal-Tec HPM 100, Leica-Microystems, Vienna, Austria; Bal-Tec HPM 010, ABRA-Fluid AG, Widnau, Switzerland available from Boeckeler Instruments, Inc., Tucson, Arizona, USA; Compact 01, Wohlwend, Switzerland available from Technotrade International, Inc., Manchester, NH, USA) and two distinct designs are being used. One (Leica, EMPACT) is based on the machine built by Riehle (Riehle and Hoechli, 1973). The machine builds up pressure on the sample and then cools it by an independent mechanism. The specimen is introduced into a small closed chamber that is first pressurized to $210 \mathrm{MPa}$, and then immediately cooled from outside to $-196^{\circ} \mathrm{C}$ by a double jet of liquid nitrogen. The other machines (Bal-Tec, Wohlwend), developed according to Moor et al. (1980), pressurize liquid nitrogen to $210 \mathrm{MPa}$ and then "shoot" it onto the sample holder to freeze the specimen. Thus, in this design the cryogen also acts as pressurizing agent. Pressurization and cooling of the sample are synchronized to occur within $20 \mathrm{~ms}$ in both systems (Fig. 2). All commercially available devices do their job reproducibly well. There are differences in size of machine and sample holder, liquid nitrogen consumption and specific sample preparation tools. It is a big advantage of the EMPACT device (Studer et al. 2001) that the sample is completely sealed with the help of socalled membrane specimen carriers during high pressure freezing. Thus, possible solvent interactions with the sample are eliminated. In the end, the choice of the most suitable machine depends on the kind of sample that needs to be processed, and on the required preparation technique.

Before being frozen in a HPF machine, the biological specimen has to be introduced into a specially designed sample holder or chamber. Different types exist that are optimized for various samples and applications. Copper tubes are used for cell suspensions or small organisms (like C. elegans; Claeys et al. 2004) and are best suited for subsequent cryosectioning (Al-Amoudi et al. 2005b). Two special tissue microbiopsy systems have been designed (Hohenberg et al. 1996; Vanhecke et al. 2003). The Vanhecke system allows the transfer of needle biopsies obtained from various tissues into specimen carriers containing a slot with the same dimensions as the biopsy-needle notch. Specimen carriers with a central cavity $(200 \mu \mathrm{m}$ deep) can hold anything from plant leaves (Pfeiffer and Krupinska 2005), small organ pieces (Shanbhag et al. 2001; Wang et al. 2005), to vertebrate embryos (Epperlein et al. 2000). Transparent sapphire discs that can be fitted into the specimen carriers are suitable substrates for cell cultures (Eppenberger-Eberhardt et al. 1991; Verkade 2008). 


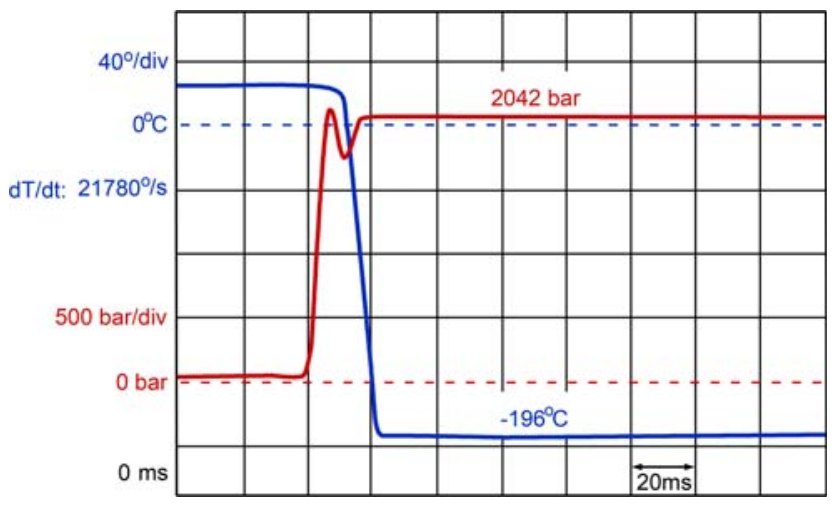

Fig. 2 Record of temperature (blue line) and pressure (red line) changes during freezing (total time $=200 \mathrm{~ms}$ ) in the EMPACT high pressure freezing machine. The temperatures and as a result the cooling rates are measured with a thermocouple located just below the specimen carriers. The pressure is measured in the pressure system that is connected to the sample. As a consequence, the pressure measured is the one that really acts on the sample, whereas the temperature record just tells us that pressure and temperature have been synchronized correctly and that the freezing cycle was technically working

Since the aim of vitrifying is to allow imaging of cellular ultrastructure close to the living state, it is of course important to keep the time between sample collection and freezing as short as possible. Concentrated cell suspensions and small organisms are easily introduced into sample holders and frozen in a HPF machine within considerably less than a minute. Cells cultured on sapphire disks can be frozen within $5 \mathrm{~s}$ with the help of the so-called rapid transfer system (RTS; Verkade 2008) of the EMPACT2 (Leica-Microsystems). Tissue samples are far more critical, because they often have to be dissected and trimmed before they can be fitted into the specimen holders. This not only takes time, but also causes cell damage that might affect the integrity of the entire tissue sample. Here, the biopsy system described above is useful by allowing sample collection and freezing within $30 \mathrm{~s}$.

After sample collection, high pressure freezing is the second step of sample preparation. A sample of $200 \mu \mathrm{m}$ thickness is cryoimmobilized within 50 ms (Fig. 2; Studer et al. 1995). The next steps are required to process the vitreous sample into sections or replicas suitable for electron microscopy. Four principally different follow-up procedures are used that are described below. Freeze fracturing (Moor and Mühletaler 1963) generates a replica of a fractured surface through the sample. Freeze substitution (Van Harreveld and Crowell 1964) and freeze drying (Edelmann 1978), respectively, result in resin-embedded samples that are suitable for conventional ultrathin sectioning. Last but not least, after mounting and trimming in a cryo-ultramicrotome the sample can be cryosectioned and the resulting frozen hydrated sections investigated on a cold stage in the electron microscope at $-170^{\circ} \mathrm{C}$ (Al-Amoudi et al. 2004; Dubochet et al. 1983).
Freeze fracturing

Originally, high pressure freezing (Moor 1987) was introduced as a cryofixation method for freeze fracturing (Moor and Mühletaler 1963). In the latter procedure, a frozen biological sample is broken open in the vacuum, and a platinum-carbon replica is prepared from the fractured sample surface that can be investigated in the electron microscope. In contrast to thin sections, freeze fracture replicas show mostly surface views of organelles and cellular membranes since the two lipid layers of a membrane tend to separate during fracturing. Thus, the method is especially suited for membrane studies, for e.g., it allows estimating the density of transmembrane protein molecules that appear as particles on a smooth lipid leaflet (Kopp 1973; Shotton et al. 1978). In the original freeze-fracturing procedure, samples were first fixed with aldehydes and soaked in cryoprotectants in order to avoid ice crystal formation during freezing, and high pressure freezing was developed to make these pretreatments obsolete. Specialized sample holders are available that allow freeze fracturing immediately after high pressure freezing (Craig et al. 1987; Walther 2003).

\section{Freeze substitution}

Freeze substitution is a hybrid method that combines the improved structural preservation of cryofixation with resin embedding (Humbel and Schwarz 1989; Van Harreveld and Crowell 1964). After cryofixation the sample is dehydrated with solvents (acetone/methanol/ethanol/) at around $-90^{\circ} \mathrm{C}$, then in most applications chemically fixed (e.g., with uranyl actetate, osmium tetroxide, and aldehydes) during the warming-up period. Osmium tetroxide starts to fix (i.e., to crosslink carbon double bonds) at $-70^{\circ} \mathrm{C}$ (White et al. 1976) and glutaraldehyde starts crosslinking at $-40^{\circ} \mathrm{C}$ (Humbel et al. 1983). The dehydrated sample is finally embedded in resins at temperatures between $-50^{\circ} \mathrm{C}$ and room temperature. At a first glance the effort to high pressure freeze and then chemically crosslink the sample may confuse. The big difference is that at room temperature the cell is fixed from the liquid phase. In freeze substitution, however, a stabilized (frozen, solid) framework is crosslinked. One important feature has to be noted that no osmotic effects can take place (Studer et al. 1992). Epoxy resins (Matsko and Müller 2005) are preferentially used for morphological analysis, and methacrylates for immunolabeling (Acetarin et al. 1986; Carlemalm et al. 1982; Newman and Hobot 1987; Newman et al. 1983; Roth et al. 1981a; Scala et al. 1992). Important to know: the freezesubstitution protocol (and there may exist about 100 different ones) determines contrast formation. In our experience this can result in very different patterns for initially identically well preserved samples (membranes with and without 
contrast; Walther and Ziegler 2002; collagen fibrils with and without water-rich "halos"; Studer et al. 1996).

\section{Freeze drying}

En bloc freeze drying of cryofixed samples before resin embedding was shown to preserve the location of diffusible ions significantly better than other methods (Edelmann 1986; Linner et al. 1986). However, the structural preservation is mostly not as good as after freeze substitution (e.g., there is shrinkage of mitochondria). However, for SIMS (secondary ion mass spectroscopy) applications the method is still used (Guerquin-Kern et al. 2005).

\section{CEMOVIS}

Cryo-electron microscopy of vitreous sections (CEMOVIS; Al-Amoudi et al. 2004) is the only one method in tissue electron microscopy where the "real" in situ structure is imaged directly. However, even such images need to be interpreted critically. In this case, the "real" structure is what remains from a sample after high pressure freezing, ultrathin sectioning and exposure to the electron beam at low temperature $\left(-170^{\circ} \mathrm{C}\right)$. In contrast to freeze-substitution or freeze-drying, in CEMOVIS only purely physical treatments are applied to the sample and no chemical interactions take place. Thus solvents, fixatives, resins, and stains cannot dehydrate crosslink and precipitate sample molecules; the main concern is damage by the electron beam. It was shown that by this method it is possible to depict the structures of distinct macromolecular assemblies (Lucic et al. 2005; Lucic et al. 2008). The correct arrangement of cadherins in the desmosome structure (Al-Amoudi et al. 2007) will be discussed in detail below.

\section{Structural preservation of high pressure frozen versus chemically prefixed tissues}

Despite of the clear advantage of cryofixation over immediate aldehyde fixation in aqueous solution, there are limitations. Because of the inherent physical limits of high pressure freezing described above, only small samples can be prepared (thickness $200 \mu \mathrm{m}$, diameter 1.3-3 mm). This is in fact a severe handicap because only very small intact organisms, organs or tissue can be fixed without preceding dissection. Possible alterations of distinct structures due to the high pressure are another concern. The two reports that we consider to be important in this respect are on the one hand the work of Leforestier et al. (1996) who showed that a liquid crystal phase of DNA did not persist during high pressure freezing, whereas slam freezing preserved the structure perfectly. On the other hand, Semmler et al. (1998) demonstrated that some (not all) distinct lipid mixtures change structure when high pressure frozen. These two described artifacts are an indication that chromatin and membranes may show pressure-induced changes in their original molecular structure.

Neither the limitations in sample size nor the chance of pressure-induced artifacts questions the fact that, for most applications, high pressure freezing leads to improved ultrastructural preservation. Nowadays, many objects under investigation that are of high interest, as for example cell cultures, can be fixed as complete entity. In all cases so far, well cryofixed samples show a better morphology when compared to chemically (aldehydes and/or osmium tetroxide) prefixed ones. The criteria for "better" are not easy to determine and are often based on theoretical or esthetical considerations. However, a few reports show ample evidence that cryofixation leads to an ultrastructure closer to the living state than immediate chemical fixation. During aldehyde and osmium tetroxide prefixation membranous structures are reorganized resulting in the formation of mesosomes (Dubochet et al. 1983; Ebersold et al. 1981), collapse of early endosomes (Murk et al. 2003), rearrangement of membrane discs of photoreceptor cells (Szczesny et al. 1996), and degradation and loss of proteins (Behrman 1984; Maupin and Pollard 1983). Different osmotic pressures (solute concentrations) in the individual cell compartments are not maintained (Studer et al. 1992). The extracellular matrix of cartilage and soybeans nodules is preserved on the ultrastructural level only after cryofixation (Studer et al. 1995, 1996). Last but not least, specimens with an almost impermeable coat such as $C$. elegans or plant pollen are practically impossible to preserve by direct aldehyde fixation. After high pressure freezing and freeze substitution, however, their ultrastructure is beautifully preserved (Hess 1993; Hohenberg et al. 1994; McDonald and Morphew 1993).

Synapses in the rat hippocampus are well preserved after high pressure freezing and freeze substitution (Fig. 3a, c; Frotscher et al. 2007). To judge the quality of preservation in comparison to aldehyde fixation we took as a reference the structural features of frozen hydrated brain sections shown by Zuber et al. (2005). After high pressure freezing membranes are smooth, the structures are not shrunken and the cytoplasm appears denser, demonstrating that there is less precipitation and loss of solid matter. The tissue is uniformly stained when high pressure frozen whereas wrinkles and empty spaces dominate the aldehyde and osmium tetroxide fixed brain tissue (Fig. 3b, d).

\section{Immunolabeling of high pressure frozen samples}

In situ localization of biomolecules by means of specific antibodies is one of the most powerful and popular 

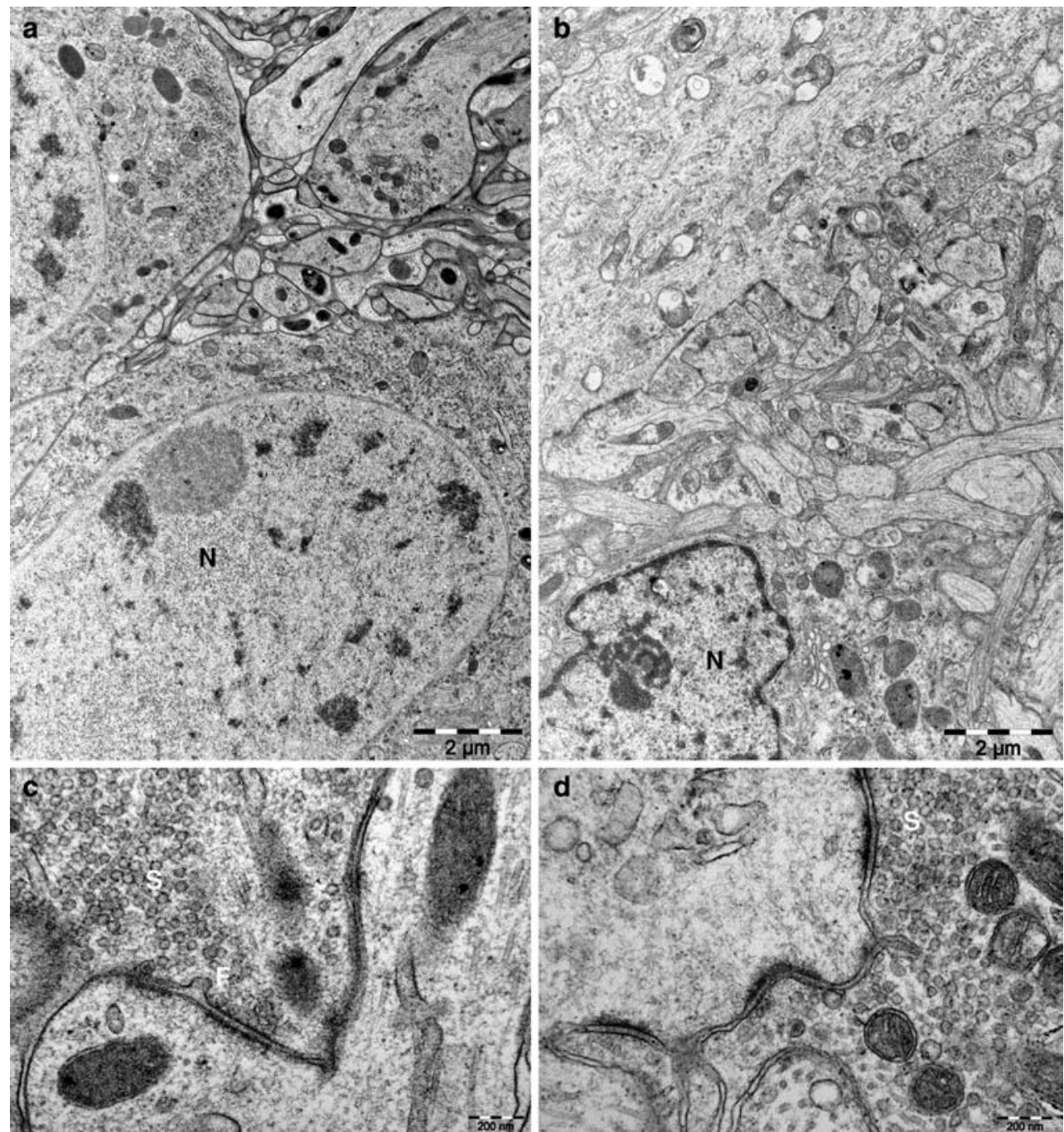

Fig. 3 Ultrastructural differences between brain tissue that was either high pressure frozen or chemically prefixed, respectively. Organotypic slice cultures were prepared from P6 rat hippocampus and maintained for 7 days in vitro before being processed for EM. a, $\mathbf{c}$ The tissue was high pressure frozen and freeze-substituted in acetone containing $2 \%$ osmium tetroxide. $\mathbf{b}, \mathbf{d}$ The tissue was directly chemically fixed with glutaraldehyde and osmium tetroxide. Note the following characteris-

techniques in cell biology. On the ultrastructural level, this method has been boosted by the development of colloidal gold-coupled protein A or secondary antibodies (Romano and Romano 1977; Romano et al. 1974; Roth et al. 1978), which allow to localize a specific antigenic site (for review see Roth 1983). Labeling efficiency depends on the specific antigen-antibody combination, the fixation and embedding protocol (pre-embedding approaches are not considered). As a rule of thumb the better the sample is fixed (and preserved) the worse is the labeling efficiency (Schwarz and Humbel 1989). In general, Lowicryl resins (Acetarin et al. 1986; Carlemalm et al. 1982; Humbel et al. 1983; Roth et al. 1981a) are better suited for successful labeling than epoxy resins because they do not crosslink epitopes tics of high pressure frozen tissue: (1) the membranes are clearly delineated, (2) synaptic vesicles $(S)$ are of uniform size and perfectly circular, (3) fusion $(F)$ of vesicles with the bouton membrane is frequently seen (catching this event may be facilitated by freezing), (4) the nuclei $(N)$ appear as "turgescent" ellipsoids without concavities indicating shrinking, (5) mass distribution appears more regular and therefore the structures are more evenly stained

(Carlemalm et al. 1982; Causton 1986). Best efficiency of labeling is usually achieved with the so-called Tokuaysu technique (Tokuyasu 1973, 1980): aldehyde prefixed, sucrose impregnated samples are frozen and cryosectioned. The sections are thawed and labeled.

To improve structural integrity and to try to maintain labeling sensitivity, high pressure frozen samples are subjected to immunolabeling. In the following, four representative examples are described in more detail where this approach has produced superior results compared to conventional methods. In one case, the ultrastructure was preserved well enough to determine the exact arrangement of a motor protein within a microtubular network (Sharp et al. 1999). By pairing excellent ultrastructure with high labeling 
efficiency, another paper demonstrates that trafficking of membrane proteins can be assessed ultrastructurally at least in a semi-quantitative way by immuno-EM (Sawaguchi et al. 2004). To label very small molecules like small hormones the chemical crosslinking of epoxy resins can be advantageous (Wang et al. 2005). COPII labeling by combining high pressure freezing with the Tokuyasu approach is the forth example discussed (Van Donselaar et al. 2007).

Sharp et al. (1999) investigated the role of bipolar kinesin KPL61F for microtuble dynamics in mitotic spindles of Drosophila embryo blastoderm. They prepared antibodies against a terminal peptide of KPL61F both in its non- and serine-phosphorylated form and found by immunocytochemistry that phosphorylated KPL61F specifically associates with spindle microtubules. For EM localization of KPL61F, Lowicryl or Epon sections from high pressurefrozen and freeze-substituted embryos were labeled with the antibodies. The phospho-peptide antibody detected KPL61F on the surface of spindle microtubules with extremely high efficiency in Lowicryl-embedded samples. On Epon sections labeling efficiency was much reduced, but because of better contrast of the microtubules they were better for statistical analysis. The KPL61F phospho-peptide epitope was localized within $10 \mathrm{~nm}$ from the microtubule surface. Moreover, a quantitative evaluation of the Lowicryl sections revealed that the observed rows of gold particles on the surface of adjacent microtubules were spaced laterally by $60 \mathrm{~nm}$ in average, corresponding to the predicted distance between antibody epitopes on the tetrameric, bipolar kinesin molecule. These data strongly supported a sliding filament model, where KPL61F crossbridges microtubules and moves parallel to them. The results also clearly demonstrated the value of the HPF approach. In this study it is interesting that the antibody against the unmodified KPL61F peptide did not label on EM sections, although it worked as well as the phosphopeptide antibody for immunofluorescence on permeabilized cells and for Western blotting. Because the two described antibody epitopes are identical except for the modification, there is no obvious reason why their accessibility or stability should differ so drastically on identically treated EM sections. Despite of the excellent results with one of the two antibodies, this example proves that it is impossible to predict whether a certain antigen-antibody combination will yield satisfying results by immuno-EM.

The work by Sawaguchi et al. (2004) shows that HPF in combination with freeze substitution and post-embedding immunolabeling can be used to study the trafficking of a membrane antigen between intracellular compartments after cell stimulation. These authors isolated gastric glands from rabbits and kept them at $37^{\circ} \mathrm{C}$ for $30 \mathrm{~min}$ in medium containing histamine for stimulation of secretion. Thereafter the glands were immediately high pressure frozen, freeze substituted, and embedded into Lowicryl or Epon. On Epon sections, the ultrastructure of various intracellular compartments in gastric parietal cells was excellently preserved and incubation with an antibody to $\mathrm{H}^{+} / \mathrm{K}^{+}$-ATPase produced very specific and efficient labeling on various intracellular membranes. By image analysis, the membrane length of different compartments was measured, and all colloidal gold particles within $20 \mathrm{~nm}$ distance from membranes were counted. Importantly, the labeling intensity of the (Golgi-derived) tubulovesicles was found to be the same in non-stimulated and stimulated parietal cells, whereas after stimulation the labeling for $\mathrm{H}^{+} / \mathrm{K}^{+}$-ATPase was increased fourfold on the intracellular canaliculi (with which the tubulovesicles fuse when stimulated). Thus, in principle, optimized cryofixation and embedding allows to follow membrane protein redistribution during cellular processes by immuno-EM in a semi-quantitative way. Due to the excellent ultrastructure, it could also be shown for the first time that $\mathrm{H}^{+} / \mathrm{K}^{+}$-ATPase localizes to specific endocytic compartments of parietal cells. In the same study, an antibody to ezrin was used to localize this actin-associated protein to the microvilli of intracellular canaliculi; however, this antibody gave satisfactory labeling only on Lowicryl sections with the disadvantage that they exhibited reduced contrast and structural preservation.

Small molecules, such as hormones and neurotransmitters can pose difficulties for immunolabeling because they can be lost during the tissue processing, although this depends on the molecules studied (Ravazzola et al. 1981; Roth et al. 1981b) The hormone mesotocin is an extremely small molecule of nine amino acids only (Cys-Tyr-Ile-GlnAsn-Cys-Pro-Ile-Gly- $\mathrm{NH}_{2}$ ) with only one primary amine group that can be fixed by aldehydes. Wang et al. (2005) described that after HPF, freeze substitution and Lowicryl embedding, the vesicles containing the mesotocin were electron-translucent and showed no immunoreactivity. When the glands, however, were embedded in Epon the secretory vesicles appeared dark and mesotocin could clearly be immunolabeled. Here, the epoxy resin acted obviously as an additional chemical crosslinker (Causton 1986; Matsko and Müller 2005; Sung et al. 1996) and was essential for a successful localization. This example clearly shows that there should be no dogmas in immunolabeling. After all, the first protein A-gold immunolabeling was performed on thin sections of epoxy resin-embedded tissue (Roth et al. 1978).

A new method has recently been developed in which HPF-fixed and freeze-substituted samples are rehydrated, sucrose/ice-embedded and cut, thus combining the advantages of rapid cryofixation with the high labeling efficiency of the Tokuyasu technique (Ripper et al. 2008; Van Donselaar et al. 2007). The Tokuyasu technique excels in visualizing membranes and in general in high labeling efficiency. The 
new method proves its value when delicate membrane interactions need to be studied, or when the object cannot adequately be fixed chemically. In combination with cryofixation, small changes or interactions between membranes can be interpreted with increased confidence (Zeuschner et al. 2006). In general, the labeling efficiency seems indeed higher with the van Donselaar approach than on resin sections after freeze substitution. It seems, however, to be lower than on samples prepared by chemical fixation and processed by the original Tokuyasu technique. An ultrastructural comparison between chemically fixed (Tokuyasu 1980) and cryofixed (Van Donselaar et al. 2007) sections shows that in the latter not only membranes seem to be straighter, but also the cytoplasm appears much denser (Fig. 4). A "disadvantage" of better preservation of cytoplasmic content is the fact that ribosomes cannot be discerned in the dense, heavily stained cytoplasm.

Immunolabeling for ultrastructural localization has still a big potential for improvement. It appears that the superior structural preservation achieved with cryofixation, especially high pressure freezing, may be combined with sophisticated immunolabeling protocols, such as genetic engineering of antigen-antibody binding sites to improve docking. This may result in almost perfect localization of small and/or globular proteins in optimally preserved samples, which so far cannot be detected by other means. Identification of proteins by tomography as shown in the next

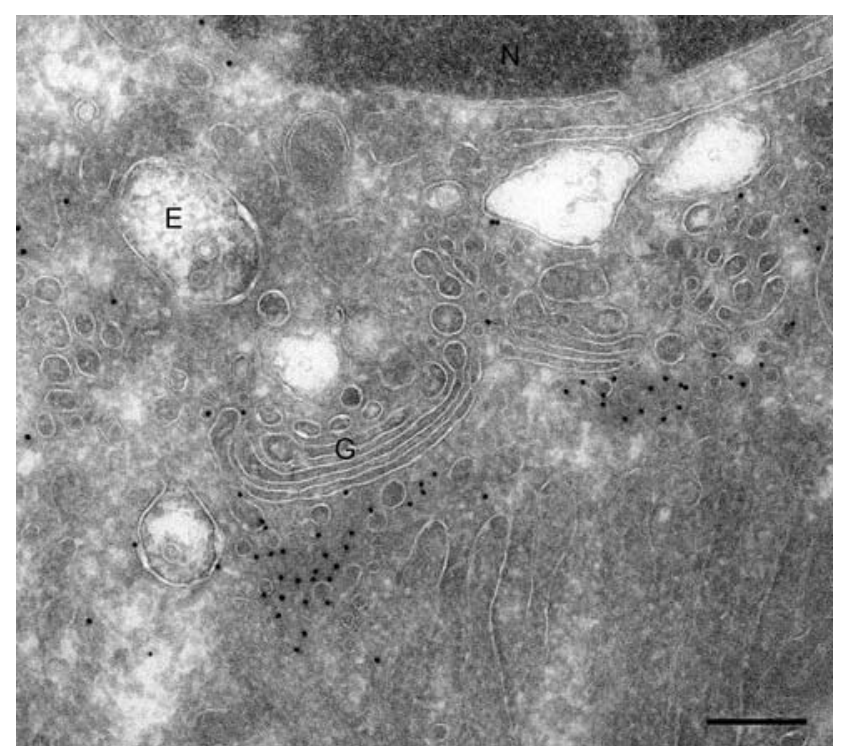

Fig. 4 COPII antigen immunolabeling shown in a mouse chondrocyte. Following van Donselaar et al. (2007) the sample was high pressure frozen, freeze-substituted, rehydrated and subjected to cryosectioning and immunolabeling according to Tokuyasu. Vesicles in the cis-Golgi region show specific labeling with immuno-gold spheres. Note the clear membrane contrast and their straight appearance. $N$ nucleus, $G$ Golgi apparatus, $E$ endosomes. Scale bar represents $200 \mathrm{~nm}$. Reproduced with permission of Wiley Inc. paragraphs, i.e., without labeling, will for a long time only be possible for large molecular assemblies with a characteristic shape.

\section{Electron tomography of high pressure-frozen sections: from tissues to molecular assemblies in situ}

Cryofixation and imaging by cryo-electron microscopy is the only method to preserve at the same time not only the molecular structure of macromolecules but also their context within the cell, and novel techniques are required to exploit the full power of this approach. For example, a new 'virtual labeling' method has been developed to identify distinct protein species within cells or tissue sections (Böhm et al. 2000; Frangakis et al. 2002). From thin layers of cells grown and cryofixed on electron microscopy grids, or alternatively from cryo-sections, cryo-electron tomograms are taken. Knowing the number of images and tilt angles, the spatial resolution for a protein of interest can be estimated. The molecular structure of the protein available from a protein data bank is reduced to the expected resolution, and a virtual template is made. Then the whole tomogram is searched with the template in all possible orientations. The place where a molecule within the tomogram fits the template is marked and thus the protein of interest can be located in all three dimensions in the tomogram (Baumeister 2002, 2005; Frangakis et al. 2002; Lucic et al. 2005; Medalia et al. 2002; Nickell et al. 2006). The limitation of this method is that the proteins must be large $\left(>2 \times 10^{5} \mathrm{Da}\right)$ and have a characteristic, unique signature in terms of shape. With increasing resolution of the tomograms, smaller proteins could be localized by the template matching method.

A recent review in this journal is entirely devoted to cryo-electron tomography in general (Lucic et al. 2008). Here, one line of research shall be described in more detail that demonstrates the power of combining high pressure freezing with electron tomography of frozen sections and molecular modeling. Among the organelles originally discovered by electron microscopy are various junctions that connect lateral surfaces of neighboring epithelial cells. Desmosomes are easily recognized as plaque-like structures between adjacent cells with bundles of intermediate (cytokeratin) filaments emanating from their electron-dense cytoplasmic surface (Drochmans et al. 1978; Waschke 2008). In electron micrographs of chemically fixed and stained epidermis, desmosomes are characterized by a gap of a constant width of $35 \mathrm{~nm}$ between adjacent plasma membranes; the only additional structure visible in classical electron micrographs is an electron-dense "midline" in the gap between the two membranes (Drochmans et al. 1978). To reveal more detail, skin samples were high pressure-fro- 
zen, freeze-substituted, embedded in Epon, and contrasted by conventional methods (He et al. 2003). After sectioning, electron tomograms of desmosomes revealed tiny filaments in the gap region that extended from the cell membranes to the midline. Their ends appeared to join at the midline in knot-like structures, forming an irregular network. This suggested that in desmosomes, the cell adhesion transmembrane proteins of the cadherin family (desmogleins and desmocollins) were arranged more or less stochastically (He et al. 2003). The picture changed when desmosomes were viewed on high pressure-frozen but unstained, frozen hydrated sections. Now, complex regular patterns of varying electron density became visible in the desmosomal gap region (Al-Amoudi et al. 2005a). In a follow-up study, electron tomography was applied to ultrathin vitrified sections through desmosomes (Al-Amoudi et al. 2007). These revealed electron-dense rod-like structures perpendicular to opposing plasma membranes, with a lateral periodicity of $7 \mathrm{~nm}$. The regularity of desmosomal structure became even more obvious when sub-tomograms extracted from small areas were rotationally aligned and averaged in the computer. In averaged images, the rods appeared to be curved and to interlock, in a stagger, at the midline with similar rods emanating from the opposite cell membrane (Fig. 5; Al-Amoudi et al. 2007).

A priori, the ultrastructural model described above was obtained in an unbiased way that did not depend on previous assumptions about cadherin or desmosome structure. Therefore, it could be used for evaluating published molecular models, by fitting them into the averaged electron tomograms (Al-Amoudi et al. 2007). Atomic models of desmogleins and desmocollins are not available, but the crystal structure of the closely related and highly homologous C-cadherin ectodomain has been solved (Boggon et al. 2002).
Fig. 5 From electron tomographs of frozen hydrated section to a molecular model of desmosome structure. a Electron micrograph of a frozen hydrated section of human skin, depicting a desmosome. Note the regularly spaced W-shape filaments (insert in a) crossing the desmosome gap. b Averaged subtomogram of desmosome section (left), and calculated density map (right). c Molecular model of two cadherin tetramers. $\mathbf{d}$ Molecular cadherin model fitted into the density map. Scale bar in a represents $35 \mathrm{~nm}$, in $\mathbf{b} 7 \mathrm{~nm}$. Reproduced from Al-Amoudi et al. (2007) with permission
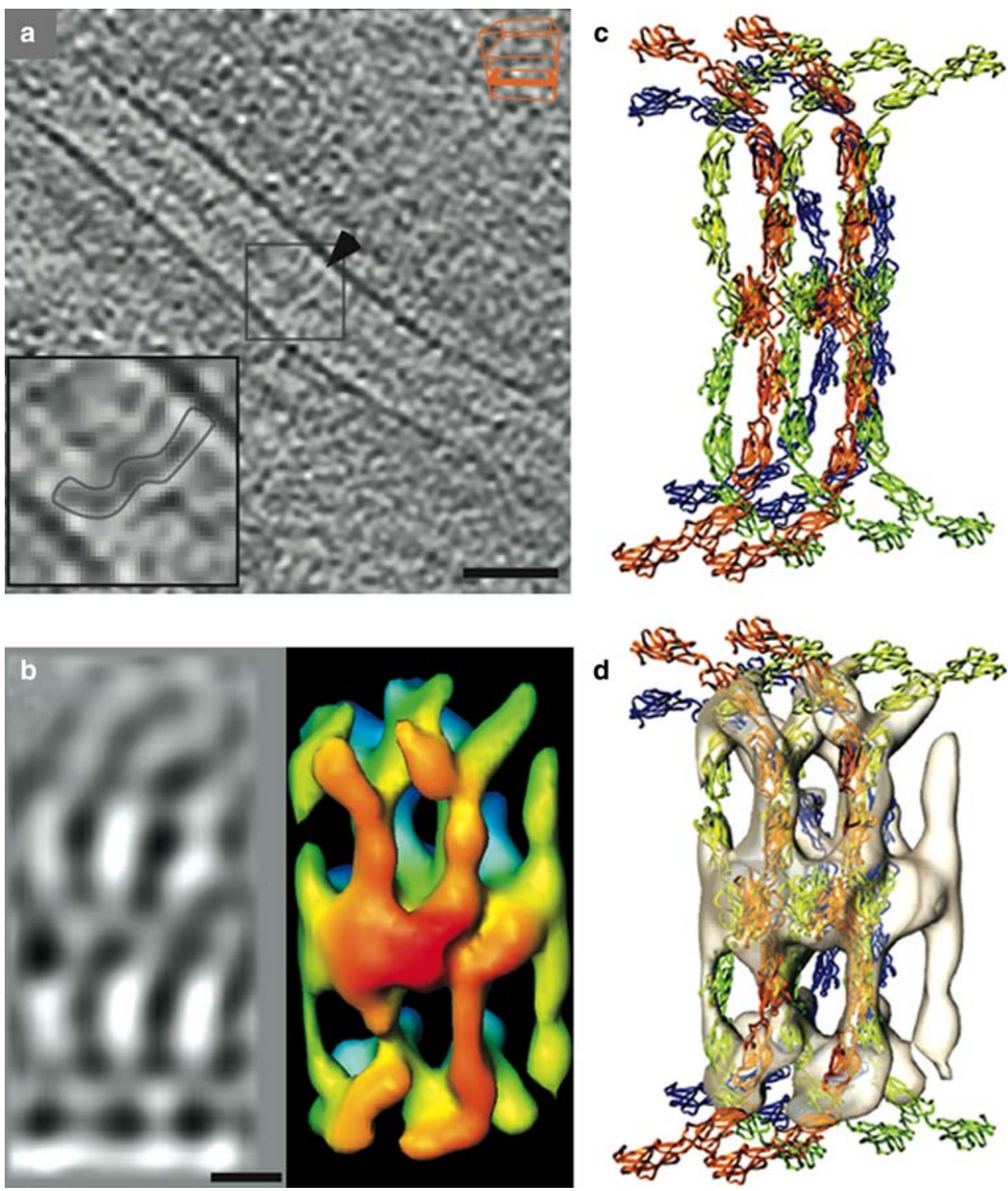
Like desmosomal cadherins, C-cadherin possesses a large ectodomain built from five consecutive immunoglobulinlike (Ig) modules. The crystal structure of complete C-cadherin ectodomains suggested that they arrange as parallel dimers interacting in cis, i.e., within the plane of the cell membrane (Boggon et al. 2002). On the other hand, a crystal structure of the N-terminal Ig domain (EC1) of N-cadherin indicated that it is able to form parallel cis- as well as antiparallel trans-interactions with its neighbors in a zipper-like manner (Shapiro et al. 1995). The EC1 had been proven essential for homophilic interactions between cadherin molecules by mutational studies, but there was disagreement about whether cadherin ectodomains would zipper rather than interact head-on (Koch et al. 1999; Pertz et al. 1999). In parallel, a model for cadherin-mediated cell-cell adhesion was derived from biochemical and ultrastructural data on the isolated proteins (Haussinger et al. 2002), as well as from functional studies with mutant cadherins (Koch et al. 1999; Pertz et al. 1999). It proposed that cadherins first form dimers by cis-interactions within the plane of one cell membrane, and that cis-dimers subsequently interact in trans via their EC1 domains to form tetramers bridging the intercellular space (Pertz et al. 1999). Finally, cadherin tetramers were thought to aggregate laterally, establishing adherens junctions (or desmosomes, respectively) between neighboring cells. The problem was that such a regular stochiometric model was difficult to reconcile with the appearance of desmosomes in electron micrographs of classically fixed (Drochmans et al. 1978) or freeze-substituted samples (He et al. 2003); however, Al-Amoudi et al. 2007) used their high pressure frozen, hydrated samples to fit the published structural models of cadherin dimer/tetramer complexes into the electron density maps of their desmosome tomograms. With only a few assumptions (e.g. concerning the angles between single cadherin domains), a surprisingly good correlation was achieved with the cis-dimer/trans-tetramer model (Al-Amoudi et al. 2007). This is one of the very recent successful attempts to bridge the gap between ultrastructure and atomic resolution for a macromolecular complex within intact tissue samples and the basis for this achievement was cryofixation by high pressure freezing.

\section{Perspectives}

At the moment high pressure freezing, as the first step of fixation after sample collection and excision, seems to be the most promising approach to preserve a sample as close as possible to a snapshot of the living state. Immunolabeling of small antigens (up to about 30,000 Da) of high pressure frozen samples has to be improved and facilitated. The most challenging follow-up procedure is cryo-electron microscopy of vitreous sections (CEMOVIS). In combina- tion with molecular modeling, tomography of such sections allows the identification and localization of macromolecular complexes in cells and tissues. Also for CEMOVIS, we have to improve and facilitate the steps to let it become a routine method. This is a big technical challenge for the next years. In our opinion, there is at the moment no equivalent alternative available to describe the molecular architecture of cells.

X-ray microscopes (Williams et al. 2008) and sophisticated STED-light microscopes (Schmidt et al. 2008) are able to depict living cells. The resolution achieved with both systems is nowadays in the range of $40 \mathrm{~nm}$. In the far future X-ray microscopes may depict ultrastructural details in the range of a few $\mathrm{nm}$ in a living cell, as it should be theoretically possible. Until then, high pressure freezing in combination with CEMOVIS will be the only way to visualize the close to native ultrastructure of living matter.

Acknowledgments The authors thank Dr. Shanting Zhao (Institute of Anatomy, University of Freiburg i.Br.) for supplying organotypic brain cultures. For technical support we thank Werner Graber and Barbara Krieger (Institute of Anatomy, University of Bern). DS was supported by the Swiss National Foundation (grant no.: 3100A0118394).

\section{References}

Acetarin JD, Carlemalm E, Villiger W (1986) Developments of new Lowicryl resins for embedding biological specimens at even lower temperatures. J Microsc 143:81-88

Adrian M, Dubochet J, Lepault J, McDowall AW (1984) Cryo-electron microscopy of viruses. Nature 308:32-36

Al-Amoudi A, Chang JJ, Leforestier A, McDowall A, Salamin LM, Norlen LP, Richter K, Blanc NS, Studer D, Dubochet J (2004) Cryo-electron microscopy of vitreous sections. Embo J 23:35833588

Al-Amoudi A, Dubochet J, Norlen L (2005a) Nanostructure of the epidermal extracellular space as observed by cryo-electron microscopy of vitreous sections of human skin. J Invest Dermatol 124:764-777

Al-Amoudi A, Studer D, Dubochet J (2005b) Cutting artefacts and cutting process in vitreous sections for cryo-electron microscopy. J Struct Biol 150:109-121

Al-Amoudi A, Diez DC, Betts MJ, Frangakis AS (2007) The molecular architecture of cadherins in native epidermal desmosomes. Nature 450:832-837

Allison DP, Daw CS, Rorvik MC (1987) The construction and operation of a simple inexpensive slam freezing device for electron microscopy. J Microsc 147:103-108

Batson PE, Dellby N, Krivanek OL (2002) Sub-angstrom resolution using aberration corrected electron optics. Nature 418:617-620

Baumeister W (2002) Electron tomography: towards visualizing the molecular organization of the cytoplasm. Curr Opin Struct Biol 12:679-684

Baumeister W (2005) From proteomic inventory to architecture. FEBS Lett 579:933-937

Behrman EJ (1984) The chemistry of osmium tetroxide fixation. In: Revel JP, Barnard T, Haggis GH (eds) The science of biological specimen preparation. SEM Inc, AMF O'Hare, Illinois, pp 1-5 
Boggon TJ, Murray J, Chappuis-Flament S, Wong E, Gumbiner BM, Shapiro L (2002) C-cadherin ectodomain structure and implications for cell adhesion mechanisms. Science 296:1308-1313

Böhm J, Frangakis AS, Hegerl R, Nickell S, Typke D, Baumeister W (2000) Toward detecting and identifying macromolecules in a cellular context: template matching applied to electron tomograms. Proc Natl Acad Sci USA 97:14245-14250

Carlemalm E, Armbruster BL, Chiovetti R, Garavito RM, Hobot JA, Villiger W, Kellenberger E (1982) Perspectives for achieving improved information by the observation of thin sections in the electron microscope. Tokai J Exp Clin Med 7(Suppl):33-42

Causton BE (1986) Does the embedding chemistry interact with tissue? In: Müller M, Becker RP, Boyde A, Wolosewick JJ (eds) The science of biological specimen preparation. SEM Inc, AMF O’Hare, Illinois, pp 209-214

Claeys M, Vanhecke D, Couvreur M, Tytgat T, Coomans A, Borgonie G (2004) High-pressure freezing and freeze substitution of gravid Caenorhabditis elegans (Nematoda: Rhabditida) for transmission electron microscopy. Nematol 6:319-327

Cope GH, Williams MA (1968) Quantitative studies on neutral lipid preservation in electron microscopy. J R Microsc Soc 88:259-277

Cope GH, Williams MA (1969a) Quantitative studies on the preservation of choline and ethanolamine phosphatides during tissue preparation for electron microscopy. I. Glutaraldehyde, osmium tetroxide, Araldite methods. J Microsc 90:31-46

Cope GH, Williams MA (1969b) Quantitative studies on the preservation of choline and ethanolamine phosphatides during tissue preparation for electron microscopy. II. Other preparative methods. J Microsc 90:47-60

Craig S, Gilkey JC, Staehelin LA (1987) Improved specimen support cups and auxiliary devices for the Balzers high pressure freezing apparatus. J Microsc 148:103-106

Drochmans P, Freudenstein C, Wanson JC, Laurent L, Keenan TW, Stadler J, Leloup R, Franke WW (1978) Structure and biochemical composition of desmosomes and tonofilaments isolated from calf muzzle epidermis. J Cell Biol 79:427-443

Dubochet J (2007) The physics of rapid cooling and its implications for cryoimmobilization of cells. Methods Cell Biol 79:7-21

Dubochet J, McDowall AW, Menge B, Schmid EN, Lickfeld KG (1983) Electron microscopy of frozen-hydrated bacteria. J Bacteriol 155:381-390

Dubochet J, Adrian M, Chang JJ, Homo JC, Lepault J, McDowall AW, Schultz P (1988) Cryo-electron microscopy of vitrified specimens. Q Rev Biophys 21:129-228

Ebersold HR, Luthy P, Cordier JL, Muller M (1981) A freeze-substitution and freeze-fracture study of bacterial spore structures. J Ultrastruct Res 76:71-81

Edelmann L (1978) A simple freeze-drying technique for preparing biological tissue without chemical fixation for electron microscopy. J Microsc 112:243-248

Edelmann L (1986) Freeze-dried embedded specimens for biological microanalysis. Scan Electron Microsc 1986(Pt4):1337-1356

Eppenberger-Eberhardt M, Riesinger I, Messerli M, Schwarb P, Muller M, Eppenberger HM, Wallimann T (1991) Adult rat cardiomyocytes cultured in creatine-deficient medium display large mitochondria with paracrystalline inclusions, enriched for creatine kinase. J Cell Biol 113:289-302

Epperlein HH, Radomski N, Wonka F, Walther P, Wilsch M, Muller M, Schwarz H (2000) Immunohistochemical demonstration of hyaluronan and its possible involvement in axolotl neural crest cell migration. J Struct Biol 132:19-32

Escaig J (1982) New instruments which facilitate rapid freezing at $83 \mathrm{~K}$ and $6 \mathrm{~K}$. J Microsc 126:221-229

Frangakis AS, Bohm J, Forster F, Nickell S, Nicastro D, Typke D, Hegerl R, Baumeister W (2002) Identification of macromolecular complexes in cryoelectron tomograms of phantom cells. Proc Natl Acad Sci USA 99:14153-14158

Frotscher M, Zhao S, Graber W, Drakew A, Studer D (2007) New ways of looking at synapses. Histochem Cell Biol 128:91-96

Galway ME, Heckman JW Jr, Hyde GJ, Fowke LC (1995) Advances in high-pressure and plunge-freeze fixation. Methods Cell Biol 49:3-19

Guerquin-Kern JL, Wu TD, Quintana C, Croisy A (2005) Progress in analytical imaging of the cell by dynamic secondary ion mass spectrometry (SIMS microscopy). Biochim Biophys Acta 1724:228-238

Haussinger D, Ahrens T, Sass HJ, Pertz O, Engel J, Grzesiek S (2002) Calcium-dependent homoassociation of E-cadherin by NMR spectroscopy: changes in mobility, conformation and mapping of contact regions. J Mol Biol 324:823-839

Hayat MA (2000) Principles and techniques of electron microscopy: biological applications, 4th edn. Cambridge University Press, Cambridge

He W, Cowin P, Stokes DL (2003) Untangling desmosomal knots with electron tomography. Science 302:109-113

Hess MW (1993) Cell-wall development in freeze-fixed pollen: Intine formation of Ledebouria socialis (Hyacinthaceae). Planta 189:139-149

Hohenberg H, Mannweiler K, Muller M (1994) High-pressure freezing of cell suspensions in cellulose capillary tubes. J Microsc 175:34-43

Hohenberg H, Tobler M, Muller M (1996) High-pressure freezing of tissue obtained by fine-needle biopsy. J Microsc 183:133-139

Humbel BM, Schwarz H (1989) Freeze-substitution for immunochemistry. In: Verkleij AJ, Leunissen JLM (eds) Immuno-gold labeling in cell biology. CRC Press, Boca Raton, pp 115-134

Humbel BM, Marti T, Müller M (1983) Improved structural preservation by combining freeze substitutuion and low temperature embedding. Beitr Elektronenmikroskop Direktabb Oberfl 16:585-594

Kanno H, Speedy RJ, Angell CA (1975) Supercooling of water to $-92^{\circ} \mathrm{C}$ under pressure. Science 189:880-881

Kellenberger E, Johansen R, Maeder M, Bohrmann B, Stauffer E, Villiger W (1992) Artefacts and morphological changes during chemical fixation. J Microsc 168:181-201

Koch AW, Bozic D, Pertz O, Engel J (1999) Homophilic adhesion by cadherins. Curr Opin Struct Biol 9:275-281

Kopp F (1973) Morphology of the plasmalemma of baker's yeast Saccharomyces cerevisiae. In: Benedetti EL, Favard P (eds) Freezeetching techniques and applications. Societé Française de Microscopie Electronique, Paris, pp 181-185

Leforestier A, Richter K, Livolant F, Dubochet J (1996) Comparison of slam-freezing and high-pressure freezing effects on the DNA cholesteric liquid crystalline structure. J Microsc 184:4-13

Linner JG, Livesey SA, Harrison DS, Steiner AL (1986) A new technique for removal of amorphous phase tissue water without ice crystal damage: a preparative method for ultrastructural analysis and immunoelectron microscopy. J Histochem Cytochem 34:1123-1135

Lucic V, Forster F, Baumeister W (2005) Structural studies by electron tomography: from cells to molecules. Annu Rev Biochem 74:833-865

Lucic V, Leis A, Baumeister W (2008) Cryo-electron tomography of cells: connecting structure and function. Histochem Cell Biol 130:185-196

Luft JH (1961) Improvements in epoxy resin embedding methods. J Biophys Biochem Cytol 9:409-414

Matsko N, Müller M (2005) Epoxy resin as fixative during freeze-substitution. J Struct Biol 152:92-103

Maupin P, Pollard TD (1983) Improved preservation and staining of HeLa cell actin filaments, clathrin-coated membranes, and other 
cytoplasmic structures by tannic acid-glutaraldehyde-saponin fixation. J Cell Biol 96:51-62

McDonald KL, Morphew MK (1993) Improved preservation of ultrastructure in difficult-to-fix organisms by high pressure freezing and freeze substitution: I. Drosophila melanogaster and Strongylocentrotus purpuratus embryos. Microsc Res Tech 24:465-473

Medalia O, Weber I, Frangakis AS, Nicastro D, Gerisch G, Baumeister W (2002) Macromolecular architecture in eukaryotic cells visualized by cryoelectron tomography. Science 298:1209-1213

Meryman HT (2007) Cryopreservation of living cells: principles and practice. Transfusion 47:935-945

Moor H (1987) Theory and practice of high pressure freezing. In: Steinbrecht RA, Zierold K (eds) Cryotechniques in biological electron microscopy. Springer, Berlin, pp 175-191

Moor H, Mühletaler K (1963) Fine structure in frozen-etched yeast cells. J Cell Biol 17:609-628

Moor H, Bellin G, Sandri C, Akert K (1980) The influence of high pressure freezing on mammalian nerve tissue. Cell Tissue Res 209:201-216

Murk JL, Posthuma G, Koster AJ, Geuze HJ, Verkleij AJ, Kleijmeer MJ, Humbel BM (2003) Influence of aldehyde fixation on the morphology of endosomes and lysosomes: quantitative analysis and electron tomography. J Microsc 212:81-90

Newman GR, Hobot JA (1987) Modern acrylics for post-embedding immunostaining techniques. J Histochem Cytochem 35:971-981

Newman GR, Jasani B, Williams ED (1983) A simple post-embedding system for the rapid demonstration of tissue antigens under the electron microscope. Histochem J 15:543-555

Nickell S, Kofler C, Leis AP, Baumeister W (2006) A visual approach to proteomics. Nat Rev Mol Cell Biol 7:225-230

Nitta K, Kaneko Y (2004) Simple plunge freezing applied to plant tissues for capturing the ultrastructure close to the living state. J Electron Microsc (Tokyo) 53:677-680

North AJ, Bardsley WG, Hyam J, Bornslaeger EA, Cordingley HC, Trinnaman B, Hatzfeld M, Green KJ, Magee AI, Garrod DR (1999) Molecular map of the desmosomal plaque. J Cell Sci 112(Pt 23):4325-4336

Palade GE, Porter KR (1954) Studies on the endoplasmic reticulum. I. Its identification in cells in situ. J Exp Med 100:641-656

Pease DC, Porter KR (1981) Electron microscopy and ultramicrotomy. J Cell Biol 91:287s-292s

Pertz O, Bozic D, Koch AW, Fauser C, Brancaccio A, Engel J (1999) A new crystal structure, $\mathrm{Ca}^{2+}$ dependence and mutational analysis reveal molecular details of E-cadherin homoassociation. Embo J 18:1738-1747

Pfeiffer S, Krupinska K (2005) Chloroplast ultrastructure in leaves of Urtica dioica L. analyzed after high-pressure freezing and freezesubstitution and compared with conventional fixation followed by room temperature dehydration. Microsc Res Tech 68:368-376

Ravazzola M, Perrelet A, Roth J, Orci L (1981) Insulin immunoreactive sites demonstrated in the Golgi apparatus of pancreatic B cells. Proc Natl Acad Sci USA 78:5661-5664

Richter T, Biel SS, Sattler M, Wenck H, Wittern KP, Wiesendanger R, Wepf R (2007) Pros and cons: cryo-electron microscopic evaluation of block faces versus cryo-sections from frozen-hydrated skin specimens prepared by different techniques. J Microsc 225:201-207

Riehle U, Hoechli M (1973) The theory and technique of high pressure freezing. In: Benedetti EL, Favard P (eds) Freeze etching techniques and applications. Société Française de Microscopie Electronique, Paris, pp 31-61

Ripper D, Schwarz H, Stierhof YD (2008) Cryo-section immunolabelling of difficult to preserve specimens: advantages of cryofixation, freeze-substitution and rehydration. Biol Cell 100:109-123

Romano EL, Romano M (1977) Staphylococcal protein A bound to colloidal gold: a useful reagent to label antigen-antibody sites in electron miroscopy. Immunochemistry 14:711-715
Romano EL, Stolinski C, Hughes-Jones NC (1974) An antiglobulin reagent labelled with colloidal gold for use in electron microscopy. Immunochemistry 11:521-522

Roth J (1983) The colloidal gold marker system for light and electron microscopy. Theory and application. In: Bullock GR, Petrusz P (eds) "Techniques in immunocytochemistry". Academic Press, New York II, pp 217-284

Roth J, Bendayan M, Orci L (1978) Ultrastructural localization of intracellular antigens by the use of protein A-gold complex. J Histochem Cytochem 26:1074-1081

Roth J, Bendayan M, Carlemalm E, Villiger W, Garavito M (1981a) Enhancement of structural preservation and immunocytochemical staining in low temperature embedded pancreatic tissue. J Histochem Cytochem 29:663-671

Roth J, Ravazzola M, Bendayan M, Orci L (1981b) Application of the protein A-gold technique for electron microscopic demonstration of polypeptide hormones. Endocrinology 108:247-253

Sartori N, Richter K, Dubochet J (1993) Vitrification depth can be increased more than 10 -fold by high pressure freezing. J Microsc 172:55-61

Sawaguchi A, McDonald KL, Forte JG (2004) High-pressure freezing of isolated gastric glands provides new insight into the fine structure and subcellular localization of $\mathrm{H}+/ \mathrm{K}+-\mathrm{ATPase}$ in gastric parietal cells. J Histochem Cytochem 52:77-86

Scala C, Cenacchi G, Ferrari C, Pasquinelli G, Preda P, Manara GC (1992) A new acrylic resin formulation: a useful tool for histological, ultrastructural, and immunocytochemical investigations. J Histochem Cytochem 40:1799-1804

Schmidt R, Wurm CA, Jakobs S, Engelhardt J, Egner A, Hell SW (2008) Spherical nanosized focal spot unravels the interior of cells. Nat Methods 5:539-544

Schwarz H, Humbel BM (1989) Influence of fixatives and embedding media on immunolabelling of freeze-substituted cells. Scanning Microsc Suppl 3:57-63 Discussion 63-54

Semmler K, Wunderlich J, Richter W, Meyer HW (1998) High-pressure freezing causes structural alterations in phospholipid model membranes. J Microsc 190:317-327

Shanbhag SR, Park SK, Pikielny CW, Steinbrecht RA (2001) Gustatory organs of Drosophila melanogaster: fine structure and expression of the putative odorant-binding protein PBPRP2. Cell Tissue Res 304:423-437

Shapiro L, Fannon AM, Kwong PD, Thompson A, Lehmann MS, Grubel G, Legrand JF, Als-Nielsen J, Colman DR, Hendrickson WA (1995) Structural basis of cell-cell adhesion by cadherins. Nature 374:327-337

Sharp DJ, McDonald KL, Brown HM, Matthies HJ, Walczak C, Vale RD, Mitchison TJ, Scholey JM (1999) The bipolar kinesin, KLP61F, cross-links microtubules within interpolar microtubule bundles of Drosophila embryonic mitotic spindles. J Cell Biol 144:125-138

Shimoni E, Muller M (1998) On optimizing high-pressure freezing: from heat transfer theory to a new microbiopsy device. J Microsc 192:236-247

Shotton D, Thompson K, Wofsy L, Branton D (1978) Appearance and distribution of surface proteins of the human erythrocyte membrane. An electron microscope and immunochemical labeling study. J Cell Biol 76:512-531

Studer D, Michel M, Muller M (1989) High pressure freezing comes of age. Scanning Microsc Suppl 3:253-268 Discussion 268-259

Studer D, Hennecke H, Müller M (1992) High pressure freezing of soybean nodules leads to an improved preservation of ultrastructure. Planta 188:155-163

Studer D, Michel M, Wohlwend M, Hunziker EB, Buschmann MD (1995) Vitrification of articular cartilage by high-pressure freezing. J Microsc 179:321-332 
Studer D, Chiquet M, Hunziker EB (1996) Evidence for a distinct water-rich layer surrounding collagen fibrils in articular cartilage extracellular matrix. J Struct Biol 117:81-85

Studer D, Graber W, Al-Amoudi A, Eggli P (2001) A new approach for cryofixation by high-pressure freezing. J Microsc 203:285294

Sung HW, Hsu HL, Shih CC, Lin DS (1996) Cross-linking characteristics of biological tissues fixed with monofunctional or multifunctional epoxy compounds. Biomaterials 17:14051410

Szczesny PJ, Walther P, Muller M (1996) Light damage in rod outer segments: the effects of fixation on ultrastructural alterations. Curr Eye Res 15:807-814

Tokuyasu KT (1973) A technique for ultracryotomy of cell suspensions and tissues. J Cell Biol 57:551-565

Tokuyasu KT (1980) Immunochemistry on ultrathin frozen sections. Histochem J 12:381-403

Van Donselaar E, Posthuma G, Zeuschner D, Humbel BM, Slot JW (2007) Immunogold labeling of cryosections from high-pressure frozen cells. Traffic 8:471-485

Van Harreveld A, Crowell J (1964) Electron microscopy after rapid freezing on a metal surface and substitution fixation. Anat Rec 149:381-385

Vanhecke D, Graber W, Herrmann G, Al-Amoudi A, Eggli P, Studer D (2003) A rapid microbiopsy system to improve the preservation of biological samples prior to high-pressure freezing. J Microsc 212:3-12

Vanhecke D, Graber W, Studer D (2008) Close-to-native ultrastructural preservation by high pressure freezing. Methods Cell Biol 88:151-164
Verkade P (2008) Moving EM: the rapid transfer system as a new tool for correlative light and electron microscopy and high throughput for high-pressure freezing. J Microsc 230:317-328

Walther P (2003) Recent progress in freeze-fracturing of high-pressure frozen samples. J Microsc 212:34-43

Walther P, Ziegler A (2002) Freeze substitution of high-pressure frozen samples: the visibility of biological membranes is improved when the substitution medium contains water. J Microsc 208:3-10

Wang L, Humbel BM, Roubos EW (2005) High-pressure freezing followed by cryosubstitution as a tool for preserving high-quality ultrastructure and immunoreactivity in the Xenopus laevis pituitary gland. Brain Res Brain Res Protoc 15:155-163

Waschke J (2008) The desmosome and pemphigus. Histochem Cell Biol 130:21-54

White DL, Andrews SB, Faller JW, Barrnett RJ (1976) The chemical nature of osmium tetroxide fixation and staining of membranes by X-ray photoelectron spectroscopy. Biochim Biophys Acta 436:577-592

Williams GJ, Hanssen E, Peele AG, Pfeifer MA, Clark J, Abbey B, Cadenazzi G, de Jonge MD, Vogt S, Tilley L, Nugent KA (2008) High-resolution X-ray imaging of Plasmodium falciparum-infected red blood cells. Cytometry A

Zeuschner D, Geerts WJ, van Donselaar E, Humbel BM, Slot JW, Koster AJ, Klumperman J (2006) Immuno-electron tomography of ER exit sites reveals the existence of free COPII-coated transport carriers. Nat Cell Biol 8:377-383

Zuber B, Nikonenko I, Klauser P, Muller D, Dubochet J (2005) The mammalian central nervous synaptic cleft contains a high density of periodically organized complexes. Proc Natl Acad Sci USA 102:19192-19197 